\title{
Model of transfection in human endometrial epithelium cells with hsa-miR-I9I-5p
}

\begin{abstract}
Background: Human endometrial cells are important in blastocyst recognition and implantation. We have recently shown that miR-191-5 $p$ secreted into culture medium by human embryos cultured and transferred to woman on the fifth day of development was associated with the percentage of pregnant $v s$. non-pregnant patients. Little is known about the regulation and expression of endometrial miRNAs induced by embryonic miRNAs in endometrial tissue. Therefore, in the present work we explored the viability and transfection of RL95-2 endometrial cell line with agomiR-191.
\end{abstract}

Results: The main results obtained in this study were: First, transfection of RL95-2 cell line with $100 \mathrm{nM}$ of lipofectamine in combination with 15,30 , and $60 \mathrm{pmol}$ of agomiR-191 for 3, 6 and 24 hours does not affect the viability of RL95-2 cells. Second, we observed expression of miR-191 with $60 \mathrm{pmol}$ of agomiR-191 in a time dependent transfection.

Conclusion: Stimulation of RL95-2 endometrial cell line with lipofectamine does not modify their viability. The transfected RL95-2 endometrial cells showed increased the expression of hsa-miR-191-5p.

Keywords: endometrial epithelium cells, lipofectamine, miRNA, transfection, cell viability

\author{
Volume 7 Issue 5 - 202I
} Ricardo Josué Acuña-González,' Irlando
Lara-Pereyra, ${ }^{2}$ Diego Iván GonzálezAzpeitia, ${ }^{3}$ Guadalupe García-López, ${ }^{4}$ Héctor Flores-Herrera'

'Department of Immunobioquímica, Instituto Nacional de Perinatología "Isidro Espinosa de los Reyes" INPerIER, México ${ }^{2}$ Hospital General de zona 252, Instituto Mexicano del Seguro Social, México

${ }^{3}$ Department of Ginecología, Hospital General de León, México ${ }^{4}$ Department of Fisiología y Desarrollo Celular, Instituto Nacional de Perinatología "Isidro Espinosa de los Reyes" INPerIER, México

\begin{abstract}
Correspondence: Héctor Flores-Herrera, Department of Inmunobioquímica, Instituto Nacional de Perinatología "Isidro Espinosa de los Reyes”, Montes Urales \#800 Col. Lomas de Virreyes CP I I000. Tercer piso de la Torre de Investigación. Ciudad de México, México, Tel/Fax +(52)5555209705, Email h.flores@inper.gob.mx
\end{abstract}

Received: October 08, 202 | | Published: October 25, 202 I

\section{Introduction}

Endometrium receptivity is crucial for successful blastocyst implantation and occurs at a specific time called the window of implantation. ${ }^{1-3}$ Which is regulated by multiple factors which include: ovarian steroid hormones; estrogen (E2) and progesterone (P4), ${ }^{4,5}$ adhesion molecules, ${ }^{6}$ and maternal immune system. ${ }^{7}$ Noncoding ribonucleic acids (RNAs) have been shown to be important epigenetic regulators in gene expression during endometrial receptivity. ${ }^{8}$ Noncoding regulatory RNA included: Long noncoding RNA (lncRNA) and long RNA pseudogenes, Enhancer RNAs, Telomerase RNA, microRNAs (miRNAs), RNA interference (RNAi), small interfering RNA (siRNA), and piwi-interacting RNA (piRNA). ${ }^{9-11}$ The miRbase database has reported over 2,500 miRNAs precursors, with diverse functions. ${ }^{12}$

Human miRNAs are regulate in gestational tissues, cell differentiation and proliferation, ${ }^{13}$ apoptosis, ${ }^{14}$ endometrial receptivity, ${ }^{15}$ and decidualization. ${ }^{16}$ Recently, Acuña-González et al., ${ }^{17}$ demonstrated the increase of hsa-miR-191-5p in human blastocyst culture medium corresponding to woman with clinical pregnancy, compared to those without sonographic evidence of gestational sac. ${ }^{17}$

Chen et al., ${ }^{18}$ demonstrated that endometrial tissue of patients with repeated implantation failure showed important changes of hsa-miR155-5p, hsa-miR20b-5p, and hsa-miR-330-5p. In addition, Raj et al., ${ }^{19}$ demonstrated that the expression of the proteins associated with the endometrial receptivity (E-cadherin, and $\mathrm{N}$-cadherine) are regulated by has-miR-149. ${ }^{19,20}$

\section{Research statement}

RL95-2 human endometrial cell line was transfected with three different concentrations of agomiR-191 15, 30 and 60 pmol for 6 hours. The cell viability and the transfection efficiency were analyzed at 3,6 , and 24 . The main hypothesis in this study was that transfection will not affect the viability of RL95-2 cell line, and second; there will be no changes in the transfection efficiency of miR-191 with the different doses used.

\section{Material and methods}

\section{Cell culture}

Human RL95-2 endometrial epithelium cell line (American Type Culture Collections, CRL-1671; Manassas, VA, USA) was cultured at a density $8 \times 10^{4}$ cells/well in 12 well plates (Conrning, Darmstadt, Germany) in a Dulbecco modified Eagle F-12 medium (DMEM-F12; ATCC, 302006; Manassas, VA, USA), supplemented with 10\% fetal bovine serum (Gibco, Bethesda, MD, USA) an 1\% penicillinstreptomycin (100 U/mL:100 $\mu \mathrm{g}$; Gibco) and incubated at $37^{\circ} \mathrm{C}$ in $5 \%$ $\mathrm{CO}_{2}$. After reaching $95 \%$ of confluence, the medium was removed and RL95-2 cells were washed twice with sterile saline solution. Subsequently, the tests for transfection were carried out which are described below.

\section{RL95-2 cells miRNA transfection}

For transfection the following groups were considered: 1) control (cells were incubated only with DMEM-F12), 2) negative control (cells were incubated with $100 \mathrm{nM}$ Lipofectamine 2000 Kit (Invitrogen, Carlsbad, CA, USA)), 3) low expression (cells were incubated with 15 pmol agomiR-191-5p (Creative Biogene Biotechnology; USA) and $100 \mathrm{nM}$ Lipofectamine), 4) moderated expression (cells were incubated with 30 pmol agomiR-191-5p and $100 \mathrm{nM}$ Lipofectamine), and 5) overexpression (cells were incubated with 60 pmol agomiR191-5p and $100 \mathrm{nM}$ Lipofectamine). At 6 hours after transfection, the culture medium was removed and the cells were washed twice 
with sterile saline solution. Finally, the RL95-2 cells were incubated for 3, 6 and 24 hours post-transfection and in each case the culture medium and cells were recovered. Four independent experiments each performed, in duplicate.

\section{RNA isolation, cDNA synthesis, and PCR-reaction}

Culture medium was recovered from all different transfection conditions and stored at $-70 \mathrm{C}$.

RL95-2 cells were washed three times with sterile saline solution. Total RNA was extracted by TRIzol reagent (InvitroGen, Carlsbad, CA, USA) as previously reported, ${ }^{17}$ and the concentration of RNA was measured as the A260/280 ration on a NanoDrop One spectrophotometer (Thermo Scientific, Waltham, MA, USA).

We transcribed using a Reverse Transcription System (Promega A3500, Madison WI, USA) and amplification using a PCR kit (Promega GoTaq Flexi DNA Polymerase M8295, Madison WI, USA), with the following forward $(\mathrm{F})$ and reverse $(\mathrm{R})$ primers (integrated DNA Technologies IDT, Coralville, IA, USA), and specific universal sequence (GTGCAGGGTCCGAGGT) was included. The primer sequence and expected size of the product were hsa-miR-191-5 $p(\mathrm{GT}$ CGTATCCAGTGCAGGGTCCGAGGTATTCGCACTGGATACG), $\mathrm{TM}=56^{\circ} \mathrm{C}, 73 \mathrm{pb}$.

Cycling parameters were as follows: denaturalization at $94^{\circ} \mathrm{C}$ for $30 \mathrm{~s}$, annealing $56^{\circ} \mathrm{C}$ for $30 \mathrm{~s}$ and elongation at $72^{\circ} \mathrm{C}$ for $30 \mathrm{~s}$. Final extension lasted $10 \mathrm{~min}$ at $72^{\circ} \mathrm{C}$ and was terminated by rapid cooling to $4^{\circ} \mathrm{C}$. We analyzed PCR products in a $4.0 \%$ agarose gel and determined their size by comparison with molecular weight standard after GelRed (Biotium, Hayward, CA, USA) using Gel Capture Acquisition software (DNA Bio-Imaging System).

\section{Cell viability assay}

To determine the effect of transfection Lipofectamine-miR-191p on RL95-2 cells the viability was determined at 3, 6, and 24 hours by colorimetric assay of 3-(4,5-di-methylathiazol-2-yl)-2,5-diphenyl-
2H-tetrazolium bromide (MMT) as previously reported by FuentesZacarias et al., ${ }^{21}$ RL95-2 cells line were washed twice with sterile saline solution, and then cultured for 3 hours in the presence of 20 $\mu \mathrm{L}(5 \mathrm{mg} / \mathrm{mL})$ of MMT in $5 \% \mathrm{CO}_{2}$ at $37^{\circ} \mathrm{C}$. Subsequently, $150 \mu \mathrm{L}$ of Dimethyl sulfoxide (DMSO; Merck KGaA, Darmstadt, Germany) was added into each well. Negative control, a mitochondrial uncoupler carbonyl cyanide m-chlorophenylhydrazone (CCCP) was dissolved in dimethylsulfoxide at a concentration of $80 \mu \mathrm{M}^{22}$ and added to cells before the incubation at $37^{\circ} \mathrm{C}$ with $5 \% \mathrm{CO}_{2}, 95$ $\%$ air. Blue formazan product in culture medium from RL95-2 cells was analyzed by spectrophotometric absorbance reading at $570 \mathrm{~nm}$ in Benchmark microplate (model 550; BioRad. Hercules, CA, USA). Three independent experiments each performed in duplicate.

\section{Statistical analysis}

All data were analyzed by one-way ANOVA with multiple comparison followed by Tukey's tests using GraphPad Prism version 8.0 (GraphPad Software, San Diego, CA, USA). All values are presented as the mean \pm standard deviation. P-values below 0.05 were considered as a statistically significant difference.

\section{Results}

Figure 1 shows the viability of RL95-2 cell line after 3, 6, and 24 hours of treatment with $100 \mathrm{nM}$ Lipofectamine alone or in combination with 15,30 , and 60 pmol of agomiR-191-5p the three independent experiments.

The viability in control RL95-2 cells after 3, 6, and 24 hours of stimulation was $0.219 \pm 0.015,0.2513 \pm 0.014$, and $0.2703 \pm 0.009$ respectively. We did not observe statistically significant differences between the transfected with respect to the control group (Figure 1A). CCCP, a mitochondrial uncoupler decreases RL95-2 cell line viability $v s$ control group (Figure $1 \mathrm{~A} ; \mathrm{p}<0.05$ ). The amplification product of hsa-miR-191-5p by PCR was visualized in all the transfection conditions, increasing after 24 hours post-transfection (Figure 1B).
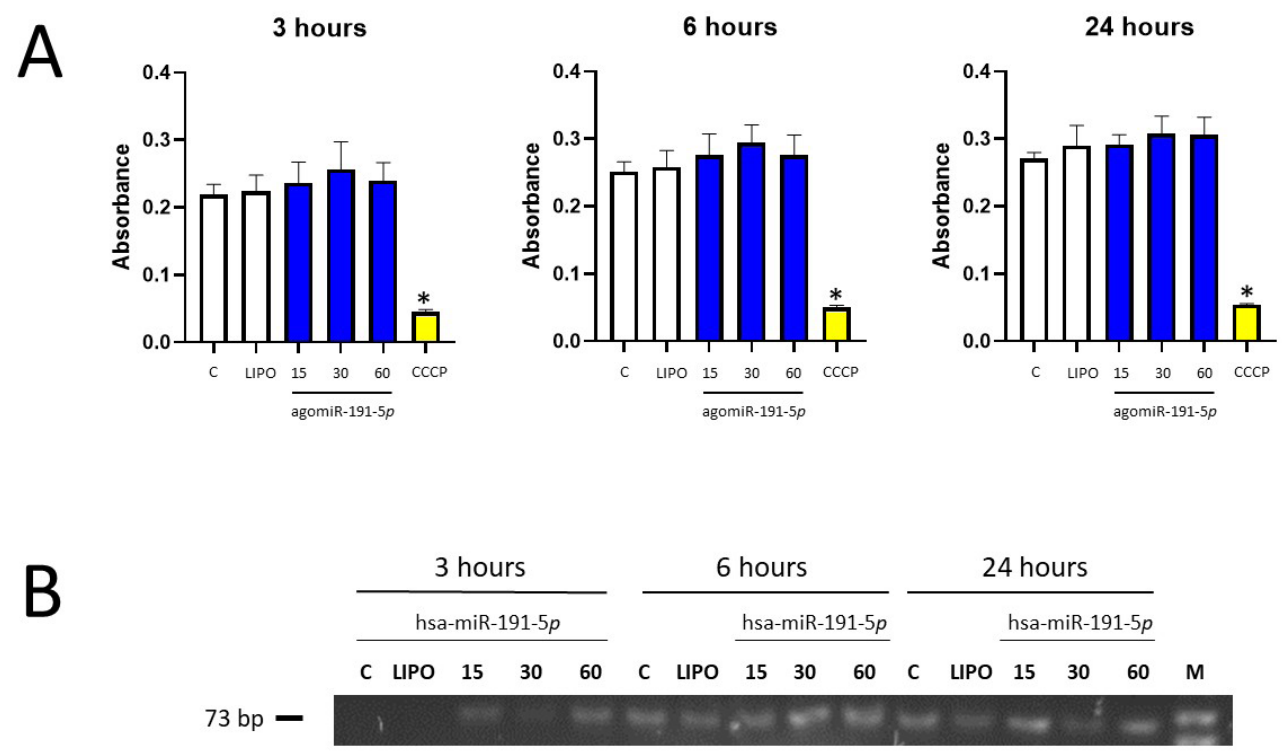

Figure I Viability of RL95-2 cells, and expression of hsa-miR-I9I-5p in the different transfection treatments. Control group (C), negative control (LIPO, Lipofectamine), and Lipofectamine in combination with 15,30, and 60 pmol of hsa-miR-19I-5p. Representative image of the post-transfection at 3, 6, and 24 hours. (A) The viability was carried out in 3 independent experiments and in none of the cases were statistically significant differences obtained between the treatments $(\mathrm{p}=0.593)$. In this set of experiments was included the negative control, a mitochondrial uncoupler carbonyl cyanide m-chlorophenylhydrazone (CCCP; yellow bar). Statistically significant difference with respect to the control group (C; $\mathrm{P}<0.05)$. Data are shown as the mean \pm standard deviation. (B) Amplification of hsa-miR-19I-5p produced fragment of 73 bp. DNA ladder marker 100 bp (M, InvitroGene). 


\section{Discussion}

Transfection assays by different methods might generate cell damage, for example damage to the cell membrane mediated by lipotoxicity, ${ }^{23}$ which depends fundamentally on the method used to introduce genetic material, ${ }^{24}$ as well as the biological characteristics of the cells under study. ${ }^{25}$ In our work we selected the lipofectamine transfection method based on previous studies, ${ }^{26-28}$ that demonstrated a transfection efficiency of $35-50 \%,{ }^{29,30}$ and viability of $50-70 \%$ of the cells when treated with transfection of single string oligonucleotides. ${ }^{30}$

Although there is information regarding the transfection of RL952 endometrial cells with Lipofectamine ${ }^{31}$ in our study, we performed the viability assay with the MMT method and it was established that the percentage of viable cells that remain in culture is greater than $90 \%$, comparing such percentage between control vs. treated cells, either with treatment lipofectamine or lipofectamine in conjunction with three doses of synthetic agomiRNA (Figure 1B). We consider of utmost importance to be able to demonstrate the safety of these compounds to have a high degree of certainty that the changes in the expression profile are due to the intervention under study and not to a toxicity effect on the cells. Subsequently, the massive expression of miRNome in human RL95-2 endometrial cells will be evaluated.

\section{Conclusion}

Lipofectamine transfection procedure does not reduce the viability in the RL95-2 endometrial cells at the different conditions of incubations and allows the incorporation of agomiR-191-5p.

\section{Acknowledgments}

This project is part of the experimental work of Ricardo J. AcuñaGonzález to obtain the degree of Doctoral of Science (514220750) from the Programa de Ciencias Médicas, Odontológicas y de la Salud, Universidad Nacional Autónoma de México (UNAM). We thank CONACyT for providing financial support for this study.

\section{Conflicts of interest}

The authors declare that they have no competing interests.

\section{Funding}

This study was supported by Grant 212250-22661 (to HFH) from Public Health of Instituto Nacional de Perinatología "Isidro Espinosa de los Reyes", Ciudad de México, México.

\section{References}

1. Giacomini E, Scotti GM, Vanni VS, et al. Global transcriptomic changes occur in uterine fluid-derived extracellular vesicles during the endometrial window for embryo implantation. Hum Reprod. 2021;36(8):2249-2274.

2. Godakumara K, Ord J, Lattekivi F, et al. Trophoblast derived extracellular vesicles specifically alter the transcriptome of endometrial cells and may constitute a critical component of embryo-maternal communication. Reprod Biol Endocrinol. 2021;19(1):115.

3. Kim SM, Kim JS. A Review of Mechanisms of Implantation. Dev Reprod. 2017;21(4):351-359.

4. Labarta E, Sebastian-Leon P, Devesa-Peiro A, et al. Analysis of serum and endometrial progesterone in determining endometrial receptivity. Hum Reprod. 2021.

5. Marquardt RM, Lee K, Kim TH, et al. Interleukin-13 receptor subunit alpha-2 is a target of progesterone receptor and steroid receptor coactivator-1 in the mouse uterusdagger. Biol Reprod. 2020;103(4):760768.
6. Bouvier S, Kaspi E, Joshkon A, et al. The Role of the Adhesion Receptor CD146 and Its Soluble Form in Human Embryo Implantation and Pregnancy. Front Immunol. 2021;12:711394.

7. Fujiwara H, Ono M, Sato Y, et al. Promoting Roles of Embryonic Signals in Embryo Implantation and Placentation in Cooperation with Endocrine and Immune Systems. Int J Mol Sci. 2020;21(5).

8. Kolanska K, Bendifallah S, Canlorbe G, et al. Role of miRNAs in Normal Endometrium and in Endometrial Disorders:Comprehensive Review. $J$ Clin Med. 2021;10(16).

9. Feng C, Shen JM, Lv PP, et al. Construction of implantation failure related lncRNA-mRNA network and identification of lncRNA biomarkers for predicting endometrial receptivity. Int J Biol Sci. 2018;14(10):1361-1377.

10. Li T, Greenblatt EM, Shin ME, et al. Cargo small non-coding RNAs of extracellular vesicles isolated from uterine fluid associate with endometrial receptivity and implantation success. Fertil Steril. 2021;115(5):1327-36.

11. Lin N, Lin JZ. Identification of long non-coding RNA biomarkers and signature scoring, with competing endogenous RNA networks- targeted drug candidates for recurrent implantation failure. Hum Fertil (Camb). 2021:1-10.

12. Kozomara A, Birgaoanu M, Griffiths-Jones S. miRBase:from microRNA sequences to function. Nucleic Acids Res. 2019;47(D1):D155-D62.

13. Li J, Wang G, Jiang J, et al. MicroRNA-127-3p regulates myoblast proliferation by targeting Sept7. Biotechnol Lett. 2020;42(9):1633-144.

14. Hui P, Wang Y, Chen B, et al. Mir-29c Expression in Glioma and Its Effects on Tumor Cell Proliferation and Apoptosis. Iran J Public Health. 2020;49(2):304-311.

15. Altmae S, Martinez-Conejero JA, Esteban FJ, et al. MicroRNAs miR30b, miR-30d, and $\mathrm{miR}-494$ regulate human endometrial receptivity. Reprod Sci. 2013;20(3):308-317.

16. Estella C, Herrer I, Moreno-Moya JM, et al. miRNA signature and Dicer requirement during human endometrial stromal decidualization in vitro. PLoS One. 2012;7(7):e41080.

17. Acuna-Gonzalez RJ, Olvera-Valencia M, Lopez-Canales JS, et al. MiR$191-5 p$ is upregulated in culture media of implanted human embryo on day fifth of development. Reprod Biol Endocrinol. 2021;19(1):109.

18. Chen $\mathrm{CH}$, Lu F, Yang WJ, et al. A novel platform for discovery of differentially expressed microRNAs in patients with repeated implantation failure. Fertil Steril. 2021;116(1):18118-18128.

19. Verma RK, Soni UK, Chadchan SB, et al. miR-149-PARP-2 Signaling Regulates E-cadherin and N-cadherin Expression in the Murine Model of Endometrium Receptivity. Reprod Sci. 2021.

20. Wang GL, Zhang CY. Sensitive detection of microRNAs with hairpin probe-based circular exponential amplification assay. Anal Chem. 2012;84(16):7037-7042.

21. Fuentes-Zacarias P, Arzate-Castaneda DA, Sosa-Gonzalez I, et al. Pseudomonas aeruginosa induces spatio-temporal secretion of IL-1beta, TNFalpha, proMMP-9, and reduction of epithelial E-cadherin in human alveolar epithelial type II (A549) cells. Acta Biochim Pol. 2021;68(2):207_ 215

22. Chaudhari AA, Seol JW, Kang SJ, et al. Mitochondrial transmembrane potential and reactive oxygen species generation regulate the enhanced effect of CCCP on TRAIL-induced SNU-638 cell apoptosis. $J$ Vet Med Sci. 2008;70(6):537-542.

23. Bauer M, Kristensen BW, Meyer M, et al. Toxic effects of lipid-mediated gene transfer in ventral mesencephalic explant cultures. Basic Clin Pharmacol Toxicol. 2006;98(4):395-400.

24. Kim TK, Eberwine JH. Mammalian cell transfection:the present and the future. Anal Bioanal Chem. 2010;397(8):3173-3178. 
25. Lesueur LL, Mir LM, Andre FM. Overcoming the Specific Toxicity of Large Plasmids Electrotransfer in Primary Cells In Vitro. Mol Ther Nucleic Acids. 2016;5:e291.

26. Han Z, Ge X, Tan J, et al. Establishment of Lipofection Protocol for Efficient miR-21 Transfection into Cortical Neurons In Vitro. DNA Cell Biol. 2015;34(12):703-709.

27. Inyawilert W, Fu TY, Lin CT, Tang PC. Let-7-mediated suppression of mucin 1 expression in the mouse uterus during embryo implantation. $J$ Reprod Dev. 2015;61(2):138-144.

28. Yu D, Zhou H, Xun Q, et al. microRNA-103 regulates the growth and invasion of endometrial cancer cells through the downregulation of tissue inhibitor of metalloproteinase 3. Oncol Lett. 2012;3(6):1221-1226.
29. Sandbichler AM, Aschberger T, Pelster B. A method to evaluate the efficiency of transfection reagents in an adherent zebrafish cell line. Biores Open Access. 2013;2(1):20-27.

30. Wang T, Larcher LM, Ma L, et al. Systematic Screening of Commonly Used Commercial Transfection Reagents towards Efficient Transfection of Single-Stranded Oligonucleotides. Molecules. 2018;23(10).

31. Lei CX, Zhang W, Zhou JP, et al. Interactions between galectin-3 and integrinbeta 3 in regulating endometrial cell proliferation and adhesion. Hum Reprod. 2009;24(11):2879-2889. 